\title{
Impact of Oral Health Education for Migrants and Refugees by Community Health Workers: What do Participants Retain?
}

Ileana Ponce-Gonzalez

Community Health Workers Coalition for Migrants \& Refugees

Allen Cheadle ( $\sim$ Allen.D.Cheadle@kp.org)

Kaiser Permanente Washington Health Research Institute

Michael Parchman

Kaiser Permanente Washington Health Research Institute

Research article

Keywords: Community Health Workers, Oral health education, Migrant and underserved populations

Posted Date: August 10th, 2020

DOI: https://doi.org/10.21203/rs.3.rs-49932/v1

License: (1) (i) This work is licensed under a Creative Commons Attribution 4.0 International License.

Read Full License 


\section{Abstract}

Objectives. An important question for oral health education is whether knowledge gained during a workshop is retained and applied in daily practice. This study assessed the knowledge retention and changes in oral health practices several months after a lay-led education workshop for migrant farmworkers.

Methods. Follow-up interviews were conducted with a random sample of participants 2-12 months post participation. Three Community Health Workers conducted the interviews using a structured Interview guide that included open-ended questions asking about both knowledge and behavior change.

Results. A total of 33 interviews were conducted with participants. The results showed a fairly high degree of retention, in such areas as general oral health knowledge, and brushing/flossing frequency and technique.

Conclusions. An interactive, lay-led oral health education program can be an effective way to increase oral health knowledge and change daily oral health practice in migrant populations.

\section{Introduction}

Oral health is one of the greatest unmet health needs of migrant farmworkers (1). Poor oral health reduces quality of life and is related to systemic chronic conditions such as stroke, heart and lung disease, and diabetes $(1,2)$. In addition to the many barriers face by migrant worker in accessing oral health care (3), a lack of knowledge about contributors to oral health, and an understanding of good oral hygiene behaviors, contribute to their well-documented poor oral health outcomes (4).

In a previous paper we described the results of an oral health education program implemented in Washington State by the Community Health Worker Coalition for Migrants and Refugees (CHWCMR) (5). Twelve interactive, lay-led oral health training workshops were conducted with 311 participants at locations throughout the state. All workshops were conducted in Spanish in rural areas and most participants were migrant farmworkers or a member of their family. A pre-post survey of participants conducted on the day of the training showed significant increases across all areas of oral health knowledge.

An important question for this and other education programs is whether knowledge gained during the workshops training is retained and applied in daily oral health practice. The purpose of this study was to assess the retention of oral health knowledge and the sustainability of changes in oral health practices several months post workshop completion. Retention in knowledge and sustained changes in practice are essential in this population, because (1) tooth caries remains the most prevalent chronic condition among migrant children; and (2) many of the adults have a chronic condition such as diabetes that increases the risk of poor oral health outcomes. In addition, since $\mathrm{CHWs}$ are trusted members of their 
communities they can serve an important role in establishing sustained healthy oral behaviors and selfmanagement to prevent and improve oral health conditions.

\section{Methods}

\section{Program description}

The oral health education program was a joint collaborative effort of CHWCMR and the Arcora Foundation. More details about the development and implementation of the program can be found in our previous paper (5). The program included both didactic and interactive components. The didactic component consisted of a presentation about key oral health knowledge and practice - e.g., brushing, flossing, implications of oral health for physical health. The interactive component involved a figure drawing exercise where participants shared thoughts on the determinants of their oral health. Each session was led by two people: (1) a master trainer with a Masters in Public Health or a Diabetes SelfManagement Program (6) credential, and (2) a lay leader who had received training for four hours in the oral health curriculum. Participants were given a \$25 stipend for attending. All of the workshops included in this paper were conducted in Spanish.

\section{Data collection}

To assess the retention of knowledge and behavior changes brought about by the oral health training program, follow-up interviews were conducted with a random sample of participants 2-12 months post program participation. Three Community Health Workers conducted the interviews, each interviewing at least 10 participants from their own workshops. The overall evaluation design and methods were reviewed and approved by the Kaiser Permanente Washington Research Institute Institutional Review Board. Participants consented to participate when they completed the pre/post surveys.

The structured Interview guide included open-ended questions asking about both knowledge and behavior change. Knowledge was assessed using a single open-ended question: "In brief, what did you learn about in the workshop?" A series of questions explored whether there were daily oral health practice or other behavior changes resulting from the workshop:

- Oral Hygiene Behaviors: "How do you take care of your teeth now, compared to before the workshop?"

- Seeking Dental Care: "Regarding going to the dentist, what has changed since you attended the workshop?"

- Diet and Food: "Regarding your diet and food habits, what has changed since you attended the workshop?"

- Barriers to dental care: "Is there any factor getting in the way of getting the dental care that you need, other than income?"

\section{Analysis}


Responses to each question were reviewed independently by two of the authors (IPG and MP) and coded into common themes. The codes were compared and then applied to a small sample of surveys together. New codes were developed, or previous codes merged, until a consensus was reached on a final set of codes that described all responses. Some of the responses by the participants resulted in more than one coded theme for a question, so the total frequencies of coded responses is greater than the final number of participants in the interviews.

\section{Results}

A total of 33 interviews were conducted with participants. Two were done 2 months after the workshop took place; the remaining 31 interviews were all done 6-12 months post-workshop. Three-quarters of the respondents $(n=24)$ were female, all but one person self-identified as Hispanic, and the mean age was 40 years.

The coded results of the interviews, along with sample responses, are shown in Table 1. Four categories of knowledge were identified in the coding: increased general knowledge about oral health $(n=16$ respondents), brushing practices $(n=13)$, how and why to floss $(n=5)$, and the importance of a healthy diet. Under behavior change there were five categories identified: Increased frequency of flossing $(n=20)$, increased brushing $(n=12)$, improvements in brushing technique $(n=3)$, and the use of mouthwash $(n=$ 2). All of those interviewed reported retention in at least one of the knowledge or behavioral practices.

\section{Table 1. Sustained knowledge and behavior changes among training participants}




\begin{tabular}{|c|c|c|}
\hline Issue/barrier & $\begin{array}{l}\# \text { of } \\
\text { mentions }\end{array}$ & Examples of responses \\
\hline \multicolumn{3}{|c|}{ Knowledge - What did you learn? } \\
\hline \multirow[t]{2}{*}{$\begin{array}{l}\text { General knowledge about } \\
\text { oral health }\end{array}$} & 16 & $\begin{array}{l}\text { "The steps to take to have good oral hygiene and } \\
\text { make it a habit" }\end{array}$ \\
\hline & & $\begin{array}{l}\text { "That oral hygiene is very important for your health in } \\
\text { general" }\end{array}$ \\
\hline \multirow[t]{2}{*}{ Brushing } & 13 & "How to brush my teeth the right way" \\
\hline & & $\begin{array}{l}\text { "How important it is to brush your teeth at least three } \\
\text { times a day" }\end{array}$ \\
\hline \multirow[t]{2}{*}{ Flossing } & 5 & "How important it is to use dental floss" \\
\hline & & "To use dental floss - I didn't use before and I do now" \\
\hline Diet & 3 & "How important it is to eat healthy" \\
\hline \multicolumn{3}{|c|}{ Behavior - How do you take care of your teeth differently? } \\
\hline \multirow[t]{2}{*}{$\begin{array}{l}\text { Increased frequency of } \\
\text { flossing }\end{array}$} & 20 & $\begin{array}{l}\text { "I floss every day, correctly, and replace my brush } \\
\text { more frequently" }\end{array}$ \\
\hline & & "I use dental floss more often" \\
\hline \multirow{2}{*}{$\begin{array}{l}\text { Increased frequency of } \\
\text { brushing }\end{array}$} & 12 & "I brush 3 times a day now" \\
\hline & & "I brush two times now and I floss frequently." \\
\hline Brushing technique & 3 & $\begin{array}{l}\text { "I brush my teeth more frequently and I do it the right } \\
\text { way now." }\end{array}$ \\
\hline Mouthwash & 2 & "I use dental floss and mouth wash now" \\
\hline
\end{tabular}

Notes: 1 - Number of times topic was mentioned across 33 participants;

\section{Discussion}

This paper presented follow-up interview results with participants in an oral health education workshop developed for migrants and refugees. The interviews were designed to assess whether knowledge and behaviors previously shown to be increased during the workshop (5) were retained several months later. The results showed a fairly high degree of retention, in such areas as general oral health knowledge, and brushing/flossing frequency and techniques. 
The results are encouraging since migrant workers, most of whom are Spanish-speaking workers, face many barriers to receiving health care in general and dental health care in particular, including lack of transportation, insurance, and sick leave; the threat of wage or job loss; language barriers; lack of regular dental practitioner; and limited clinic hours. In addition to these barriers in access, many migrant workers lack basic oral health knowledge, including the relationship between sweet foods and caries and the positive effects of good oral hygiene and fluoride on dental health and overall health (4).

Oral health training and education offers an important avenue to increasing knowledge about good oral health practices (7), and this was one of the first published evaluations we are aware of for education programs in migrant populations led by community health workers and promotoras de salud, rather than dental professionals (dentists or dental hygienists). During the last three years, CHWCMR conducted 32 oral workshops with a total of 697 participants living in rural and low-income communities in Washington State from 2017-2019. Overall, our positive findings for knowledge gain reported in a previous paper, and the retention of knowledge and behaviors reported here, support the idea that migrant populations may be better reached by education programs led by community health workers and promotoras de salud, especially those programs using an interactive approach (8).

There are several limitations that should be noted. The interviews were conducted with a relatively small sample of participants. There is likely social desirability reporting bias as participants attempt to demonstrate that they were good students and learned something in the workshops. All of the information about retention was self-reported since we had no way of observing oral health behaviors directly. Finally, this was a community-based study that relied on the lay leaders to do the data collection. All of the lay leaders received training in interviewing the participants, but there may have been inconsistencies in the way the interviews were done.

Despite the limitations, this study demonstrated that an interactive, lay-led oral health education program can be an effective way to promote sustained improvements in oral health knowledge and behavior in migrant populations.

\section{Abbreviations}

CHWCMR - Coalition for Migrants and Refugees

CHW - Community Health Worker

\section{Declarations}

Funding: Research reported in this article was funded through a grant from the Arcora Foundation.

Ethics approval and consent to participate. The evaluation design and methods were reviewed and approved by the Kaiser Permanente Washington Research Institute Institutional Review Board. 
Participants consented to participate when they completed the pre/post surveys. None of the participants were minors.

Consent for publication: Not applicable

Availability of data and material: The datasets used and/or analyzed during the current study are available from the corresponding author on reasonable request.

Competing interests: The authors declare that they have no competing interests

Funding: This study was funded by the Arcora Foundation, Seattle, WA

Authors' contributions: IPG, AC, MP all contributed to the following: conception and design of the study, data analysis and interpretation, drafting the article, and giving final approval of the version to be submitted.

Acknowledgements: Research reported in this article was funded through a grant from the Arcora Foundation. Thanks to Stacy Torrance from the Arcora Foundation and Dr. Carlos Mejia, Chief Medical Officer for CHWCMR, for their significant contributions to the project and this study. We are also very grateful for the participation and support of the members of the CHW Coalition for Migrants and Refugees who participated in this study, without them this work would not be possible. They are truly making a difference in their local communities.

\section{References}

1. Quandt SA, Clark HM, Rao P, Arcury TA. Oral health of children and adults in Latino migrant and seasonal farmworker families. Journal of immigrant and minority health. 2007;9(3):229-35.

2. Casanova L, Hughes FJ, Preshaw PM. Diabetes and periodontal disease: a two-way relationship. British dental journal. 2014;217(8):433-7.

3. Hansen E, Donohoe M. Health issues of migrant and seasonal farmworkers. Journal of health care for the poor and underserved. 2003;14(2):153-64.

4. Woolfolk MP, Sgan-Cohen HD, Bagramian RA, Gunn SM. Self-reported health behavior and dental knowledge of a migrant worker population. Community dentistry and oral epidemiology. 1985;13(3):140-2.

5. Ponce-Gonzalez I, Cheadle A, Aisenberg G, Cantrell LF. Improving oral health in migrant and underserved populations: evaluation of an interactive, community-based oral health education program in Washington state. BMC oral health. 2019;19(1):30.

6. Lorig KR, Ritter P, Stewart AL, Sobel DS, Brown BW, Jr., Bandura A, et al. Chronic disease selfmanagement program: 2-year health status and health care utilization outcomes. Medical care. 2001;39(11):1217-23. 
7. Nakre PD, Harikiran AG. Effectiveness of oral health education programs: A systematic review. Journal of International Society of Preventive \& Community Dentistry. 2013;3(2):103-15.

8. Chang CP, Barker JC, Hoeft KS, Guerra C, Chung LH, Burke NJ. Importance of Content and Format of Oral Health Instruction to Low-income Mexican Immigrant Parents: A Qualitative Study. Pediatric dentistry. 2018;40(1):30-6. 